\title{
RIESGOS Y MEDIDAS PREVENTIVAS SOBRE USO DE REDES \\ SOCIALES POR PARTE DEL ESTUDIANTADO QUE CURSA \\ EDUCACIÓN SECUNDARIA EN EL DISTRITO DE HORQUETAS, SARAPIQUÍ, HEREDIA, COSTA RICA
}

\author{
RISKS AND PREVENTIVE MEASURES ON THE USE OF SOCIAL \\ NETWORKS BY THE STUDENT WHO ATTENDS SECONDARY \\ EDUCATION IN THE DISTRICT OF HORQUETAS, SARAPIQUÍ, \\ HEREDIA, COSTA RICA
}

\author{
Ileana Schmidt-Fonseca ${ }^{1}$ \\ Rodolfo León-Anchía ${ }^{2}$ \\ Cristel Astorga-Aguilar ${ }^{3}$ \\ Jorge Manuel Luna-Angulo ${ }^{4}$
}

\begin{tabular}{|l|l|}
\hline Recibido: 10.05 .19 & Aprobado: 24.11.19
\end{tabular}

DOI: $10.15517 /$ isucr.v20i42.41850

\section{Resumen}

El objetivo principal de esta investigación es analizar el uso de redes sociales en línea entre el estudiantado que cursa educación secundaria y diversificada, mediante el establecimiento de riesgos y medidas preventivas para una correcta comunicación. La investigación corresponde a un estudio de enfoque cuantitativo y de carácter explicativo, la población estuvo compuesta por 1895

\footnotetext{
${ }^{1}$ Costarricense. Docente Sección Regional Huetar Norte y Caribe, Universidad Nacional, Costa Rica Email: ileana.schmidt.fonseca@una.cr, ORCID: https://orcid.org/0000-0001-6227-3299

${ }^{2}$ Costarricense. Docente Sección Regional Huetar Norte y Caribe, Universidad Nacional, Costa Rica. Email rodolfo.leon.anchia@una.cr, ORCID: https://orcid.org/0000-0002-2701-8038,

${ }^{3}$ Costarricense. Docente Sección Regional Huetar Norte y Caribe, Universidad Nacional, Costa Rica. Email: cristel.astorga.aguilar@una.cr, ORCID: https://orcid.org/0000-0002-1151-9954

${ }^{4}$ Costarricense. Docente Sección Regional Huetar Norte y Caribe, Universidad Nacional, Costa Rica. Email: manuel.luna.angulo@una.cr
} 
estudiantes distribuidos en el III nivel de Educación básica y Diversificada, correspondiente a colegios diurnos del Circuito Educativo 02 del Cantón de Sarapiquí, por lo que se optó por una muestra estadística estratificada de 320 estudiantes. Como resultados, se determina que el 99\% de los encuestados utiliza dispositivos electrónicos para comunicarse por internet, con un $96 \%$ el teléfono celular. Se identifica que el $75 \%$ aprendió solo a utilizar internet y un $95 \%$ emplea redes sociales, un 96\% WhatsApp, un 86\% Facebook, el 67\% Instagram y un 31\% Snapchat. Asimismo, se evidencia que el $83 \%$ de los estudiantes se encuentra solo cuando accede a redes sociales y sólo el $33 \%$ de las instituciones educativas los forma en este tema, aunado a que un $80 \%$ de los padres de familia no establece controles en su uso. Se concluye que el estudiantado de secundaria utiliza principalmente el teléfono celular para comunicarse y acceder a redes sociales en línea como WhatsApp, Facebook e Instagram, asimismo, se establecen diferencias en relación con conocer y aplicar políticas de seguridad y privacidad en su uso, se demuestra falta de conocimiento por parte de los participantes en la acción educativa: el docente, el estudiante y los padres de familia, en cuanto a riesgos y medidas preventivas al momento de comunicarse por medio de redes sociales.

Palabras clave: medios sociales; tecnología de la información; enseñanza secundaria; seguridad de los datos.

\title{
Risks and preventive steps on the use of social networks by the student body who takes secondary education in Horquetas District, Sarapiqui, Heredia, Costa Rica
}

\begin{abstract}
The main objective of this research is to analyse the use of online social networks among the student body who takes secondary education, through the establishment of risks and preventive steps for a correct communication. The research was conducted under a quantitative approach with a explicative position. The population was formed by 1895 students, distributed in the III cycle of basic education and diversified education, from day high schools of the educative district 02, Sarapiquí canton, this is why it was opted to take a stratified statistic sample of 320 students. As a result, it is determined that the $99 \%$ of the interviewees use electronic devices to communicate through internet, with a $96 \%$ the cellular phone. It is identified that $75 \%$ learnt only to use internet and a $95 \%$ uses social networks, a 96\% whatsapp, 86\% facebook, 67\% Instagram, and a $31 \%$ snapchat. Moreover, it is evidenced that $83 \%$ of the students are alone when using social networks and only $33 \%$ of the educative institutions taught them about this topic. Apart from that, $80 \%$ of
\end{abstract}


the parents do not establish controls on its use. In conclusion, the student body of secondary uses mainly the cell phone to communicate and access social networks online, such as: Whatsapp, Facebook, and Instagram. In addition, it is established some differences on the relation to know and apply security and privacy policies on the use of those means of communication, it is shown the lack of knowledge by the participants on the educative action: the teacher, student and parents, with regards to the risks and preventive steps when communicating through social networks.

Keywords: social means; information technology; secondary teaching; data security.

Introducción

Actualmente, la utilización de las Tecnologías de la Información y la Comunicación (TIC) en contextos académicos son cada vez mayores, el Sexto Informe del Estado de la Educación (2017) resalta la relevancia de su uso para incrementar la posibilidad de los estudiantes resilientes en todas las disciplinas, aumentado las posibilidades de superar la adversidad y alcanzar el éxito académico. No obstante, aunque estas son de suma importancia para los procesos de aprendizaje, existen diferencias en la utilización académica por parte de los educandos, ya que aquellos que se enfrentan a un contexto adverso las utilizan para chatear o jugar videojuegos y no para su desarrollo cognitivo por medio de búsqueda de información y lectura de noticias en línea. (Sexto Informe del Estado de la Educación, 2017)

La situación anterior, demanda un acompañamiento tanto del centro educativo por medio de los docentes, como de los padres de familia, se debe incentivar el uso de las tecnologías hacia la investigación y disminuir el uso ocioso y recreativo que, si bien es importante, no se puede convertir en el fin único, en razón de los peligros y riesgos que implica una incorrecta manipulación; tal es el caso del uso de las redes sociales sin supervisión y establecimiento de políticas de seguridad y privacidad de los datos, máxime cuando se trata de personas menores de edad.

Es importante tener claridad en cuanto al éxito de las medidas preventivas en el uso de las tecnologías y específicamente sobre las redes sociales; para lograr acciones significativas se requieren docentes, padres de familia y una sociedad en general formada y capacitada en los peligros y riesgos que implica que los adolescentes gestionen procesos sociales y de investigación por medio de las diferentes plataformas en línea. 
En este artículo se presentan los resultados obtenidos de una investigación realizada con el propósito de analizar el uso de redes sociales en línea entre el estudiantado que cursa educación secundaria y diversificada en el Distrito de Horquetas de Sarapiquí, mediante el establecimiento de riesgos y medidas preventivas para una correcta comunicación.

El sistema educativo costarricense se encuentra organizado en niveles de escolaridad: preescolar, educación básica (primaria y secundaria), diversificada y superior. La Educación General Básica se brinda de manera obligatoria y gratuita, compuesta por seis años de primaria y tres años de secundaria.

La educación inicial corresponde a la preescolar y se brinda a menores de seis años, la educación primaria comprende un periodo de seis años; la educación secundaria inicia en promedio a los 12 o 13 años; por su parte la educación diversificada compone los últimos dos o tres años de secundaria y la educación superior comprende la formación a nivel universitario.

Para efectos de esta investigación, se trabajó con estudiantes de III nivel de Educación Básica (sétimo, octavo y noveno) y educación diversificada (décimo y undécimo año) pertenecientes a colegios académicos del Ministerio de Educación Pública ubicados en el Distrito de Horquetas en Sarapiquí.

Entorno de la investigación

El estudio se realizó con estudiantes de secundaria residentes en Sarapiquí, cantón número 10 de la provincia de Heredia, creado mediante Ley $\mathrm{N}^{\circ} 4671$ del 18 de noviembre de 1970 e integrado por 5 distritos: Puerto Viejo, Horquetas, La Virgen, Llanuras de Gaspar y Cureña.

Según datos de la Municipalidad (2019), Sarapiquí cuenta con un área de 2140.54 km2 que lo convierte en uno de los cantones más extensos de nuestro país, representando el $4.62 \%$ del territorio nacional y el $82 \%$ de la provincia de Heredia; cuenta con una población total de 53.596 habitantes, el $80 \%$ de la población está ubicada en dos de los cinco distritos: Puerto Viejo y Horquetas, siendo el distrito de Horquetas el de mayor población con un $42 \%$ del total.

El $89.6 \%$ de la población es considerada rural y de ella el $81 \%$ es dispersa; el $19 \%$ se concentra en tres pequeños poblados rurales, el 10.4\% de la población es urbana y se distribuye en un 3\% en los centros de población más desarrollados y el 7.4\% restante se ubica en la periferia. Según información de la Municipalidad, el Índice de Desarrollo Social del cantón de Sarapiquí es 
de 21,2 y ocupa el puesto 68 de un total de 82 municipios del país, posiciones que ubican al cantón con un bajo y muy bajo desarrollo social.

Por su parte, Horquetas, es el segundo distrito en importancia del cantón de Sarapiquí, cuenta con mayor número y densidad población que el distrito de cabecera, Puerto Viejo. Tiene 37 centros de población, siendo Río Frío una de las localidades más grandes del distrito y Colonia La Victoria el centro de población donde se ubica la Sección Regional Huetar Norte y Caribe de la Universidad Nacional.

El proceso de investigación se llevó a cabo en circuito educativo 02, este circuito cuenta con 40 instituciones educativas entre escuelas y colegios, todas ubicadas en el distrito de Horquetas. El Circuito se caracteriza por tener instituciones de diversas modalidades, que van desde escuelas unidocentes, colegios académicos y ambientalistas y liceos rurales, así como el sistema de Centro Integrado de Educación de Adulto, CINDEA.

La mayoría de las instituciones educativas, cuentan con cierto grado de antigüedad y la mayoría tiene una infraestructura modesta, atienden a la población local que presentan las condiciones socioeconómicas antes descritas.

\section{Marco referencial}

Las redes sociales en la actualidad son utilizadas como parte de la cotidianidad, tanto a nivel social, familiar, económico, religioso, educativo y demás áreas, transformando el proceso de la comunicación por los hábitos adquiridos en la ejecución de múltiples actividades por medio de las aplicaciones que se brindan.

Haciendo un análisis de la historia de las redes sociales en Internet existen algunas particularidades, como por ejemplo los servicios que se brindan al usuario: foros o mensajería privada, o bien la plataforma sobre la que se implementan, sin embargo; todas tienen como utilidad fundamental el establecimiento de relaciones personales y el intercambio de información. El servicio de red social en Internet es definido como:

Una plataforma web cuyo fin es la creación de comunidades en línea mediante la representación de las conexiones personales que los usuarios disponen los unos de los otros. En estos servicios se puede compartir información mediante la utilización de servicios agregados de mensajería personal, 
microblogging, publicación de fotografías, formación de grupos de interés, etc. (Ros Martín, 2009, p.554)

En relación con los usos que brinda la juventud a las redes sociales, se pueden mencionar una gran diversidad de actividades a realizar, entre ellas: prácticas de socialización, búsqueda de pareja, entretenimiento, actividades lúdicas, estar en contacto con personas cercanas, crear nuevas amistades, espacios de expresión y discusión, desarrollo de actividades académicas, foros, búsqueda de empleo o para estar en el auge de la conversación (López González y Alarcón Montiel, 2016).

El uso de internet y la Web 2.0, han modificado las tradiciones a nivel cultural, dejando atrás las publicaciones impresas, los discos y casetes, las fotografías e incluso las salas cinematográficas. Actualmente, sobresale la economía de las palabras y la necesidad de hacerlas llegar rápido al destinatario; las TIC han acelerado una revolución que gira en torno a la transformación de los mecanismos de producción, almacenamiento, difusión y acceso a la información; y por ende en las formas de comunicarnos. La experiencia en aspectos como el ocio, las comunicaciones personales, el aprendizaje y el trabajo se han modificado a raíz de la aparición de nuevos actores: internet, la telefonía móvil, los videojuegos y aplicaciones digitales. (Area y Pessoa, 2012, p).

El estudio de PROSIC (2016), sobre tenencia de tecnologías digitales en adolescentes, indica: "Casi la totalidad de encuestados posee un teléfono celular propio correspondiendo al 97,1\%” (p.108) y continúa diciendo, "un 97,1\% posee conexión a Internet en su teléfono, convirtiéndose en la principal tecnología para el acceso a Internet.” (p.108). Esto convierte el teléfono celular en el medio de comunicación más importante entre los jóvenes.

Sobre las redes sociales que más accesan los adolescentes en nuestro país, Astorga y Schmidt (2019), indican: “con datos del estudio realizado por RED506 durante el año 2016; donde se consultó “¿cuáles redes sociales utilizó en los últimos 30 días?”, se obtuvo que el 90 \% utiliza Facebook, $58 \%$ WhatsApp y el $18 \%$ Instagram. En otros estudios, se resalta, además, que la red Snapchat es una red que viene emergiendo vertiginosamente." (p. 7). Esto se confirma en el estudio de PROSIC (2016), en el capítulo de “Adolescencia, Socialización y TIC”, en sus resultados sobre esta población encontró que: "En cuanto a los usos de Internet, las actividades primordiales se dirigen a las redes sociales" (p.110), y más adelante indica: "Referente a las aplicaciones 
consultadas que permiten la comunicación, la más utilizada es WhatsApp seguida por Facebook, mientras que la que menos se reporta es Twitter". (p.110)

La Web 2.0 es nombrada como la red social ya que nos permite estar en contacto permanente con otros usuarios que comparten mismos intereses y problemáticas por medio de la construcción de comunidades o grupos de comunicación horizontal, con la posibilidad de que cualquier individuo pueda interaccionar y compartir información con muchas personas, de forma fácil, en directo y sin intermediarios. (Area y Pessoa, 2012)

Riesgos en el uso de las redes sociales

Cuando se habla de redes sociales y personas menores de edad, la temática de riesgos asociada a su manipulación es realmente significativa, en mayor escala cuando se carece de formación en seguridad y privacidad en aplicaciones virtuales. La diversidad, alcance y características de las redes sociales pueden presentar impactantes riesgos para las personas que las utilizan; Internet presenta peligros parecidos a los que se sufren fuera del hogar: secuestros, extorsiones, amenazas y violaciones a la intimidad.

El contexto familiar, económico, social y educativo donde se desarrolle la persona menor de edad cumple un papel trascendental y a partir de ahí la demanda de las capacidades y habilidades para una correcta manipulación pueden marcar la diferencia.

La sociedad en general se enfrenta a diferentes problemáticas asociadas con el uso y abuso de Internet por parte de estudiantes relacionadas con la sobreinformación:

Una nueva generación de niños y adolescentes acostumbrados al uso de la tecnología, son nativos digitales que ven en el ciberespacio un mundo perfecto para la socialización, así como una fuente inagotable de información. Pero los contenidos que se generan en este espacio, muchas veces no suelen ser los más adecuados ni desde el punto de vista ético o moral, ni desde el científico. (Morales, 2014, p. 23)

Parte de los peligros de las redes sociales obedecen a acciones violentas por una mala utilización, causando daños a los usuarios; situaciones que generalmente inician en forma de juego, de diversión y de burla (Dorantes Carrión, 2016). 
Algunos de los riesgos más comunes a los que se enfrentan los y las adolescentes son los siguientes:

\section{Ciberbullying}

Hasta hace relativamente poco tiempo, parecía imposible que el acoso, matonismo o bullying se diera utilizando como herramienta "principal" una computadora o un teléfono inteligente dotados de internet. Ahora bien, la computadora, el celular y el internet, son solo el medio para ejecutar el bullying, mas no lo que lo propicia, pues lo que llevo las cosas hacia la aparición del concepto de ciberbullying, fue el uso cada vez más frecuente y naturalizado de los medios mencionados para realizar labores tan cotidianas como la comunicación y el entretenimiento.

La ciberviolencia o violencia virtual es definida como la "forma en que los medios de comunicación (Internet, telefonía móvil, sitios web y/o videojuegos online) pueden favorecer la violencia e incluso ejercerla sobre distintos grupos de personas” (Arab y Díaz, 2015, p. 10).

Arab y Díaz (2015), hacen referencia a las formas de manifestación de este riego "publicar en Internet una imagen, video, "memes", datos privados y cualquier información que pueda perjudicar o avergonzar a alguien o hacerse pasar por otra persona creando un perfil falso, ya sea para exponer aspectos privados de ella o agredir a terceros"( p.10).

\section{Grooming}

Referente a este riesgo Morales (2014), indica, "Este tipo de acoso inicia en un espacio virtual y a través de un medio tecnológico, pero se convierte en una amenaza totalmente real, además de que posibilita el intercambio de información digital entre redes de pederastas o de pornografía infantil”". (p. 23). Lo delicado del Grooming reside en que la manipulación, casi siempre a niños y personas de muy corta edad, busca en la mayoría de los casos, consolidar un encuentro personal, para perpetrar una trasgresión.

Es definido como "conjunto de estrategias que una persona adulta desarrolla para ganar la confianza del/la joven a través de Internet,... adquiriendo control y poder sobre él/ella, con el fin último de abusar sexualmente de él/ella” (Arab y Díaz, 2015, p.10). Detrás de este comportamiento, hay personas con psicopatologías complejas, cuyas acciones terminan en una 
trasgresión de las leyes y con consecuencias judiciales para el agresor y consecuencias psicológicas de corto, mediano y largo plazo para las víctimas.

\section{Sexting}

Es definido por Arab y Díaz (2015), como una práctica que “consiste en compartir imágenes de tipo sexual, personal o de otros, por medio de teléfonos o Internet. El riesgo, es que las imágenes sean publicadas y viralizadas sin permiso. Con ello la intimidad queda expuesta a la mirada pública”. (p.10)

El sexting, cuando es de común acuerdo, es una muestra clara de la falta de educación en ciberseguridad, de la falta de conocimientos sobre el internet, sus alcances y riesgos y del exceso de confianza por parte de quienes lo practican, pues en la mayoría de los casos, a diferencia de las prácticas expuestas anteriormente, en el sexting por lo general, hay un acuerdo consensuado entre las partes que participan. Esta participación sin reparo, muchas veces, se debe a la falsa creencia de que el contenido enviado, puede ser eliminado y una vez borrado, desaparece totalmente, no obstante; no es tan sencillo, la información puede quedar accesible tanto en una de las vías o partes participantes, así como en el ciberespacio, por tanto, es información asequible y vulnerable.

Ahora bien, en el caso de que las imágenes sean de terceras personas y no medie consentimiento en su trasiego, el peligro aumenta, la agresión y la violación a la intimidad es mayor y si eventualmente la información se viraliza, el perjuicio aumenta exponencialmente para la persona que está siendo víctima.

\section{Ciberadicción o conducta adictiva a Internet}

Este riesgo hace referencia a un patrón de comportamiento "caracterizado por la pérdida de control sobre el uso de Internet. Esta conducta conduce al aislamiento y al descuido de las relaciones sociales, de las actividades académicas, de las actividades recreativas, de la salud y de la higiene personal”. (Arab y Díaz, 2015, p.10)

Cualquier adicción es peligrosa, sobre todo porque afectan de manera integral al ser humano y su entorno tanto inmediato y mediato; una adicción además es peligrosa, pues se puede desarrollar a cualquier edad y en cualquier entorno social y económico.

El control sobre el uso de internet es necesario en todas las edades, sin embargo, las edades más vulnerables están en el rango de la niñez y la adolescencia, ya que además de generar 
conductas como las citadas, de aislamiento y descontrol de las relaciones humanos, genera severos problemas de salud; la obesidad infantil está asociada a una conducta sedentaria, que a su vez, está estrechamente ligada a hábitos relacionados con el uso desmedido de teléfonos inteligentes, tabletas y computadoras con acceso a internet.

Medidas preventivas en el uso de redes sociales: ciberseguridad

Las personas menores de edad deben estar facultadas con un conjunto de habilidades, destrezas y conocimientos que les permitan insertarse en entornos virtuales a través de las redes sociales.

El uso de redes sociales por parte de la juventud responde a tendencias hacia un cierto exhibicionismo de las opiniones, fotografías, canciones, páginas web, entre otros, a los demás. Situación que demanda la formación de usuarios en temáticas relacionadas con "socialización en comunidades virtuales, mediante el desarrollo de competencias de comunicación, donde primen la empatía, los valores democráticos y la cooperación con los otros, así como la conciencia de lo que debe ser público y/o privado”. (Area y Pessoa, 2012, p.17)

Internet presenta amplias posibilidades para la comunicación, brindando el acceso a la información y aportando elementos tecnológicos para el desarrollo social y cultural, sin embargo; también facilita las conductas negativas mediante la violencia virtual y el acoso cibernético; provocado por la falta de formación en su utilización. Es importante el estableciendo de normas para el uso responsable de estos recursos. (Morales, 2014)

Se debe considerar que las redes sociales se transforman constantemente, por lo que la formación debe ser continua y sistemática, brindando herramientas clave que sirvan de insumo para la búsqueda de alertas en caso de presentarse alguna situación que ponga en peligro el bienestar integral de la persona menor de edad.

Algunas de las estrategias para intervenir ante casos de ciberbullying, haciendo referencia a Morales (2014), pueden ser las siguientes: evaluar el acoso cibernético por medio de un diagnóstico, realizar estudios que permitan analizar la brecha digital y el acceso de los estudiantes a la red (para definir las formas de acoso), capacitar a través de cursos y talleres al personal educativo en la temática de acoso cibernético (se requiere que conozcan las plataformas y recursos con los que cuenta Internet), elaborar normas institucionales para el castigo del ciberacoso, 
reglamentar el uso de la tecnología, establecer normas para la manipulación de los canales potenciales de acoso cibernético: teléfonos celulares, iPads, iPods, tabletas, consolas portátiles de videojuegos y computadoras portátiles, dedicar un tiempo de clase al tema del acoso cibernético, cibercultura y ciberética, así como realizar actividades académicas apoyadas en las TIC (aprendizaje colaborativo y cooperativo).

Conjuntamente, se puede mostrar a los estudiantes que existen otros usos de las TIC, aparte de los que se enfocan en los procesos de socialización lúdica, como por ejemplo crear un grupo en Facebook para realizar actividades de aprendizaje, donde el docente pueda identificar fácilmente cuando una persona está siendo acosada o está generando violencia a través de este medio, también mejorar el uso de la red de forma crítica y constructivista incitando a los educandos a formar grupos en alguna red social donde se puedan discutir diferentes problemáticas sociales. (Morales, 2014)

De manera adicional, es importante realizar guías específicas para los padres de familia sobre el ciberacoso y cómo intervenir, ya que muchos no saben ni conocen los alcances de Internet, pensando que están seguros en casa sin permitirles salir a la calle, lamentablemente, existen en la red formas de violencia y abuso peor. (Morales, 2014)

En el caso de las redes sociales que más usan los adolescentes en nuestro país por ejemplo tienen como configuración predeterminada la total apertura de la información personal del usuario en la red:

En cuanto a las normas de privacidad y seguridad, la mayoría de las redes sociales permiten, de forma predeterminada, que cualquiera pueda ver el perfil y las publicaciones, cualquier persona puede ser buscada y encontrada, cualquier persona que siga a otra puede ver su historia, cualquier persona puede enviarle un mensaje privado y cualquier persona pueda ver la información personal. (Astorga y Schmidt, 2019, p. 18)

Por ejemplo, Facebook, WhatsApp e Instragram, permiten al usuario realizar una configuración personal para proteger su seguridad y privacidad que incluye: para poder restringir quién tiene acceso a su información persona, quien puede ver sus historias o contenidos de su perfil, quién puede buscarlos, entre otras restricciones básicas.

\section{Metodología}


Este es un estudio de enfoque cuantitativo, dado que "usa la recolección de datos para probar hipótesis, con base en las mediciones numérica y el análisis estadístico, para establecer patrones de comportamiento y probar teorías" (Hernández y otros, 2006, p.5)

De carácter explicativo ya que busca dejar en manifiesto el comportamiento a nivel de privacidad y seguridad en el uso de las redes sociales, así como las causas de estas prácticas, pues se espera conocer no solo sus experiencias, sino que orientación recibieron sobre los temas de ciberseguridad, los menores de edad de Horquetas de Sarapiquí que cursan III Nivel de Educación Básica y la Educación Diversificada.

Bajo la hipótesis de que "No hay una orientación explícita por parte de los padres, ni del centro educativo, sobre los riesgos que corren en las redes sociales, ni cómo protegerse", se busca explicar el fenómeno y la exposición que tienen los jóvenes menores de edad a estos peligros cibernéticos.

El estudio se realizó en el Circuito Educativo 02 del Cantón de Sarapiquí, a los Centros Educativos del Ministerio de Educación Pública que imparten III nivel de Educación Básica y Diversificada. La población está definida como los jóvenes menores de edad que cursan III nivel de Educación Básica y Diversificada, pertenecientes a una institución educativa ubicada en el circuito 02 del cantón de Sarapiquí.

Esta población se compone de 1895 estudiantes distribuidos en los tres grados del III nivel de Educación básica y dos grados de Diversificada, correspondiente a seis colegios diurnos, por lo que se optó por una muestra estadística estratificada por colegio y por nivel, dando como resultado un total de 320 estudiantes, con una certeza del 95\% y un margen de error de más menos de $5 \%$.

Tabla 1

Estudiantes encuestados por institución educativa

\begin{tabular}{lcc}
\hline \multicolumn{1}{c}{ Institución } & $\begin{array}{c}\text { Número de } \\
\text { Estudiantes }\end{array}$ & Porcentaje \\
\hline Liceo Río Frío & 192 & $60 \%$ \\
Liceo Ambientalista & 60 & $19 \%$ \\
Liceo Rural La Conquista & 28 & $9 \%$ \\
Liceo Rural Las Colonias & 11 & $3 \%$ \\
Liceo Rural Islas Del Chirripó & 21 & $6 \%$ \\
Colegio Humanístico de Sarapiquí & 8 & $2 \%$ \\
Total & $\mathbf{3 2 0}$ & $\mathbf{1 0 0 \%}$ \\
\hline
\end{tabular}

Nota: Fuente propia de la investigación. 
Esta muestra fue consultada, durante el mes de Setiembre de 2019, mediante un cuestionario que según explica Arias (2006), es "la modalidad de encuesta que se realiza de forma escrita mediante un instrumento o formato en papel contentivo de una serie de preguntas. Se le denomina cuestionario autoadministrado porque debe ser llenado por el encuestado, sin intervención del encuestador." (p. 75). En esa misma explicación el autor amplia que actualmente pueden ser también de formato digital.

El instrumento fue completado por los encuestados de manera presencial en cada institución educativa de interés del estudio, de forma voluntaria y anónima, aplicados por los investigadores, posteriormente los datos obtenidos fueron procesados mediante el programa informático Microsoft Excel y Formularios de Google. Seguidamente, con base en la información se realizó estadística descriptiva, y se elaboraron gráficos y tablas para facilitar el análisis y síntesis de los datos, así como extraer resultados que permitieran brindar las conclusiones y recomendaciones respectivas.

Análisis y resultados

En relación con la utilización de dispositivos electrónicos para comunicarse por internet, el 99\% de los estudiantes encuestados indica utilizarlos, un 38\% emplea la computadora, un $96 \%$ el teléfono celular, un $6 \%$ la tablet y el $3 \%$ play station, situación sustentada en el estudio de PROSIC (2016).

Cuando se les consulta quien les enseñó a utilizar internet, el 75\% señala que aprendió solo y un $22 \%$ con algún familiar, tal como se refleja en la gráfica1. Este resultado es el primer argumento que soporta la hipótesis planteada, de que estos jóvenes incursionan en el uso de las redes sociales a través de internet sin una orientación explícita para su uso.

\section{Gráfica 1}

Persona que enseñó la utilización de internet, 2019 

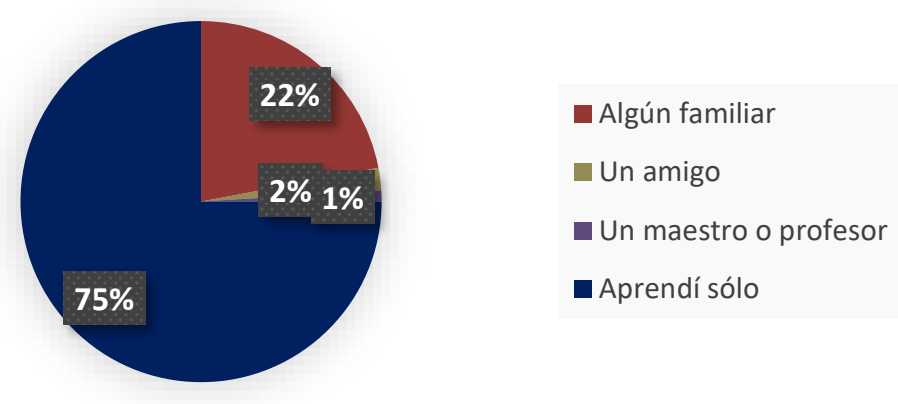

Nota: Fuente propia de la investigación.

Tras la pregunta de si saben que es una red social, el 95\% indica que Sí, sin embargo; cuando se les solicita a los jóvenes que describan su significado solo un $1.6 \%$ de todas las respuestas lo asocian con algo de peligro o de lo que deben tomar medidas de protección. El 56\% lo relaciona con comunicarse, el 22\% lo vincula con familia y amigos, el $11 \%$ con información y conocimiento; resultados que coinciden con Morales (2014), cuando nos habla de esta generación nativa digital poco consciente de los peligros en la red.

Asimismo, el 95\% de los encuestados utiliza redes sociales para comunicarse por internet. Cuando se les pregunta cuál red social utiliza, la gráfica 2 muestra que entre las más utilizadas están con un 96\% WhatsApp, un 86\% Facebook, el 67\% Instagram y un 31\% Snapchat, con una participación mucho menor Twiter y Messenger con un 3\%, lo que corresponde a las tendencias mencionadas en el estudio PROSIC (2016) y por Astorga y Schmidt (2019).

\section{Gráfica 2}

Redes sociales utilizadas por el estudiantado de secundaria, 2019

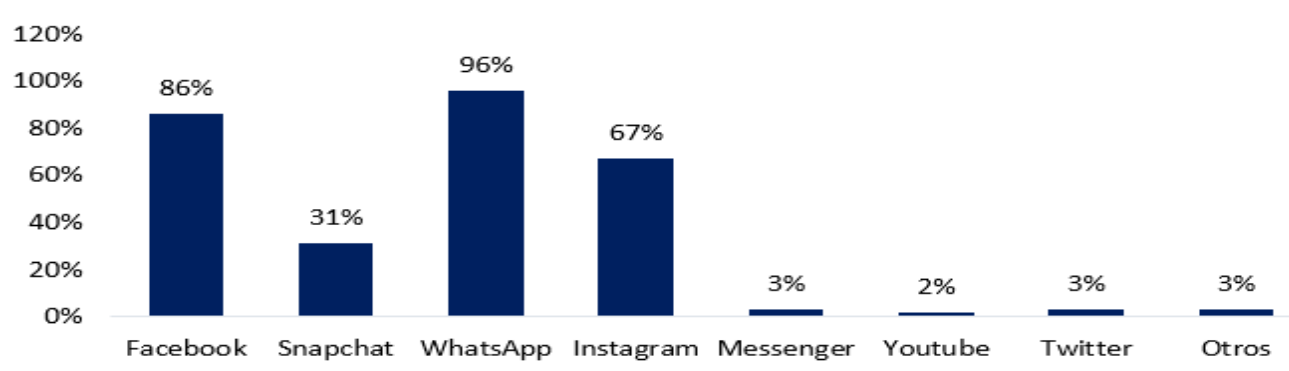

Nota: Fuente propia de la investigación. 
El 83\% de los estudiantes se encuentra solo, cuando accede a redes sociales, seguido de un $47 \%$ con un amigo. Cuando se les pregunta con qué tipo de personas se comunican con mayor frecuencia por redes sociales, la gráfica 3 muestra que el $74 \%$ indica realizarlo con amigos y solo el $4 \%$ con desconocidos. Sin embargo; en el caso de con quién se comunican con menor frecuencia, un $69 \%$ indica con desconocidos y un 19\% con familia. Este comportamiento sin importar la frecuencia evidencia la práctica de contactar con desconocidos, la cual es considerada riesgosa.

\section{Gráfica 3}

Tipo de personas con las que se comunican los encuestados por redes sociales, 2019

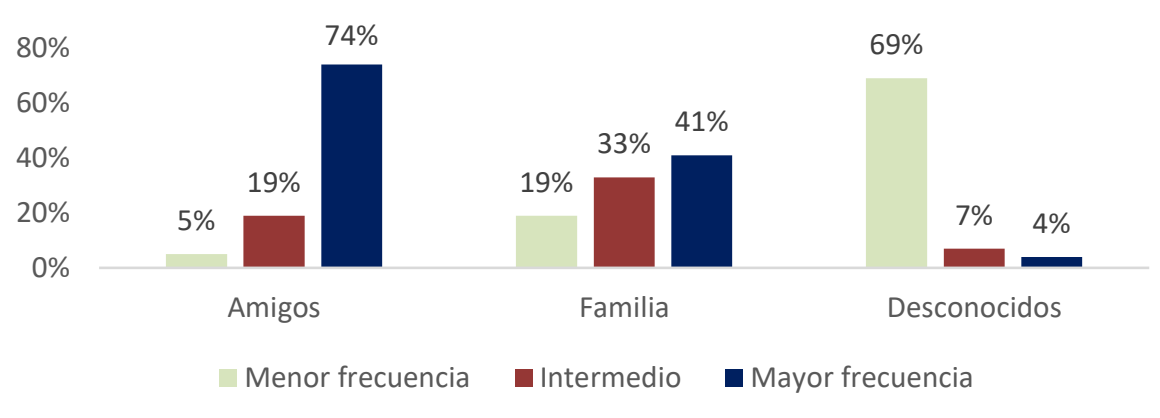

Nota: Fuente propia de la investigación.

Al consultar sobre políticas de seguridad, en la gráfica 4, para el caso de Facebook, el 56\% de los encuestados, indica que, si aplica, sin embargo, cuando se les consultó si conocían las políticas de esta red social el $76 \%$ afirmó conocerlas, es decir, casi un 20\%, no aplica medidas de seguridad aun conociéndolas. El comportamiento es similar tanto con el WhatsApp con 18 puntos porcentuales de diferencia entre los que dice conocer y los que realmente aplican. En el caso de Instagram, los porcentajes entre la aplicación y el conocimiento, tiene la misma tendencia, existe 
un sesgo de un 17\%. Con Snapchat ocurre similar, con el agravante que sólo un 30\% había indicado conocer las políticas y un porcentaje de $22 \%$, es decir $8 \%$ menos, dice aplicarlas.

\section{Gráfica 4}

Políticas de seguridad y privacidad aplicadas por red social, 2019

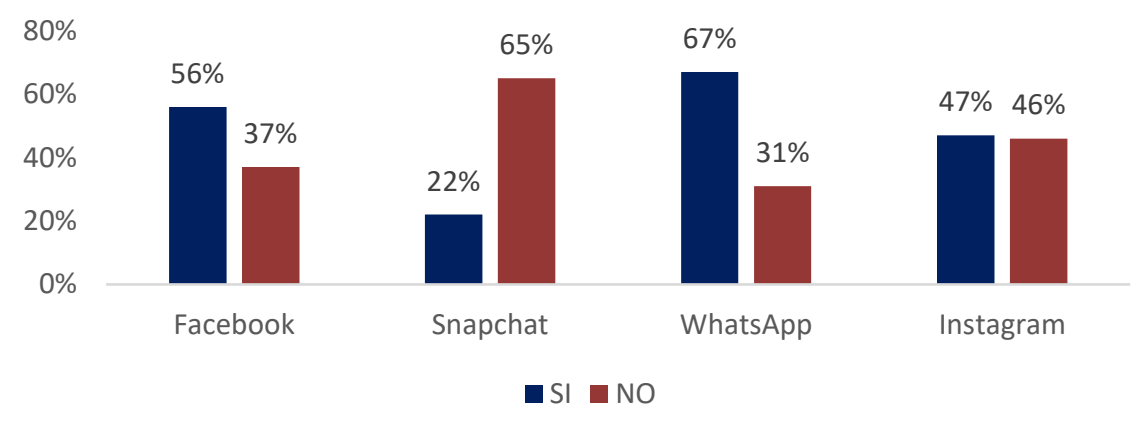

Nota: Fuente propia de la investigación.

Cuando se les pregunta cuáles medidas de seguridad son las que aplican, los que destacaron como con mayor porcentaje son; $16 \%$ aplican bloqueo y perfil privado, el 6\%, utiliza contraseñas para protección de cuentas, $28 \%$ aplican políticas de privacidad en sus publicaciones y fotos. Con porcentaje muy bajos, $0,10 \%$ no compartir contraseñas, $1,5 \%$ mencionó no enseñar datos personales; $1 \%$ el bloqueo de estados de WhatsApp; el 3\% indicó no hablar con desconocidos. Nuevamente alerta el hecho que los porcentajes que aplican acciones concretas de seguridad no superan el $28 \%$ en ninguna medida aplicada, lo que contrasta con las cifras que indican conocer las medidas (86\%) y los que dicen aplicarlas (67\%), en el caso del WhatsApp, que es el que mencionan. Otro hecho que llama la atención es el hecho de que solo un 3\% resalta no hablar con desconocidos.

Al consultar sobre situaciones que han vivido, tales como: ¿No me han aceptado en la lista de contactos de algún chat o red social? Un 66\% indicó que nunca fueron excluidos de un chat y un $34 \%$ responde al menos pocas veces, muchas veces o siempre. Ante la pregunta de si ¿Ha recibido insultos a través de mensajes cortos de texto? Un 54\% indica que nunca, pero un $46 \%$ dice que como mínimo pocas veces, muchas veces o siempre.

En un segundo momento, se les encuesta a los jóvenes si habían sido víctimas de algunos de los peligros presentes en las redes sociales, a lo que indicaron: Ciberbullying, un 90\% expresó nunca haberlo sufrido, un $8 \%$ pocas veces y un 2\% algunas veces. Sobre el acoso, $94 \%$ respondió que nunca, $5 \%$ dijo que pocas veces y solo un $1 \%$ indicó que algunas veces ha sufrido acoso. Con 
pornografía infantil, los resultados fueron, un 2\% manifestó que pocas veces y un $98 \%$ dijo que nunca estuvo expuesto al tema. Sobre el Sexiting, solo 2\% manifestó siempre estar expuesto al tema, $3 \%$ dijo que pocas veces tiene contacto con el tema y un 95\% que no practica este peligro, los datos son congruentes con las respuestas de los apartados anteriores. En cuanto al Grooming, el $90 \%$ dijo no haber sufrido del tema, solo el $7 \%$ que pocas veces, el $2 \%$ algunas veces y solo un 1\% dijo siempre. En cuanto al peligro de Ciberadicción a las Redes Sociales, 84\% indicó que no tiene problema con el tema, un 10\% que pocas veces, el $5 \%$ algunas veces y solo el $1 \%$ expone que puede tener problemas con esto.

Como última sección para conocer qué tanto están presentes estos peligros entre los jóvenes, se les preguntó si conocían a alguien que hubiese sufrido de estos peligros en las redes sociales. En la gráfica 5 se muestran los resultados, un $31 \%$ afirma conocer a personas con Ciberadicción y 15\% conocer de algún amigo o familiar que enfrentó el Grooming, un 16\% manifiesta tener conocidos que practican Sexiting y un $10 \%$ que si conoce casos de pornografía infantil. Con el acoso un 37\% y con el Ciberbullying un 33\% afirma conocer de casos cercanos. Esto refleja un porcentaje superior a $30 \%$ en los casos de Acoso, Ciberbullying y Ciberadicción.

\section{Gráfica 5}

Riesgos sobre la utilización de redes sociales: amigos o familiares, 2019

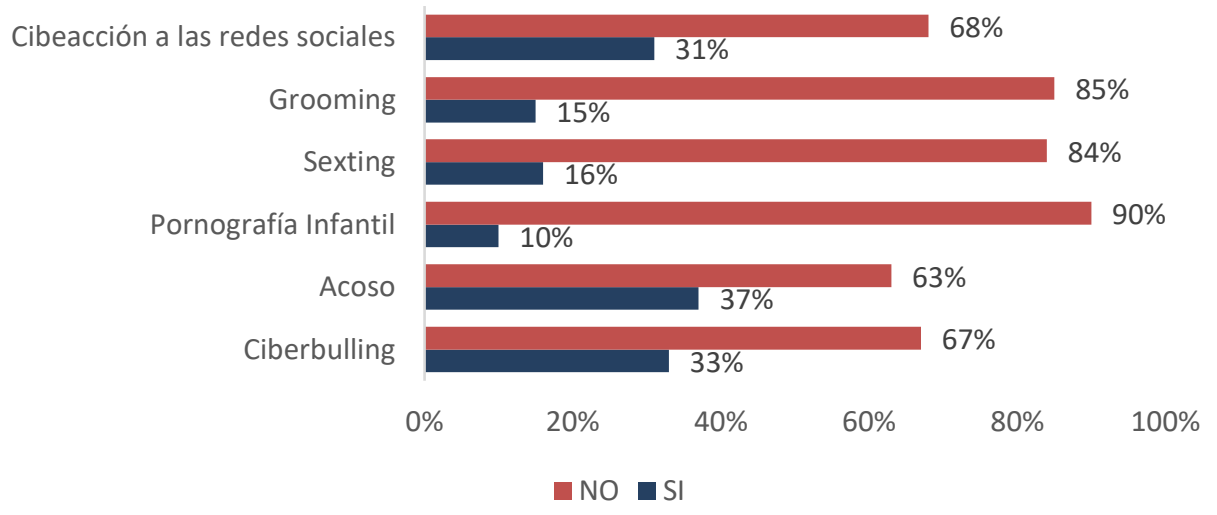

Nota: Fuente propia de la investigación.

En el tema sobre formación preventiva en entornos virtuales, se les pregunta si les han explicado sobre peligros en redes sociales, de los 320 encuestados el 68\% expresa que en sus respectivos colegios les han explicado sobre los riesgos a los que se enfrentan al utilizar las redes 
sociales, sin embargo al cruzar este porcentaje de estudiantes con los colegios provenientes, son estudiantes de dos instituciones, es decir de seis colegios investigados, solo en el $33 \%$ forma a los estudiantes en este tema.

Otro línea de investigación fue qué acciones para formar en ciberseguridad realizan los padres de familia, se encontró a una ausencia de controles y conocimiento por parte de los encargados, donde alrededor de un $80 \%$ no impone lineamientos a los jóvenes como limitar horas de uso de redes sociales, control de acceso a contenidos, entre otros, sin embargo, los estudiantes indicaron que en el 91\% de los hogares si les han explicado los riesgos a los que se enfrenta al utilizar las redes sociales, lo que refleja una sesgo entre hablar de un tema y realmente dar un proceso de formación a los hijos.

Para finalizar, se recogieron una serie de recomendaciones sugeridas por los 320 estudiantes, con respecto al uso de redes sociales por parte de menores de edad. Las respuestas se dividieron en cuatro grandes ejes:

Tabla 2

Recomendaciones aportadas por los estudiantes sobre ciberseguridad

\begin{tabular}{l}
\hline \multicolumn{1}{c}{ Ejes } \\
\hline Controles de privacidad ante y con personas desconocidas \\
Controles en cuanto a las imágenes, videos y comentarios que se envían y reciben \\
por medio de las redes sociales \\
Controles y supervisión que deben tener los padres de familia sobre los menores \\
de edad, en cuanto al uso de las redes sociales. \\
Procesos de información y formación sobre el uso, responsabilidades y peligros \\
de las redes Sociales
\end{tabular}

Nota: Fuente propia de la investigación.

Por ejemplo, sobre el eje número 1, la recomendación que alcanzó el mayor porcentaje y similitud de respuestas fue: no aceptar ni hablar con personas desconocidas, donde $25 \%$ de los encuestados, reconoce el peligro que representa, tener personas desconocidas en sus redes sociales y además reconocer como altamente peligroso y entablar conversaciones con esas personas. Sobre el eje dos un $14 \%$ de los estudiantes advierten y recomiendan tener cuidado tanto con lo que buscan, como con lo que se dice, se comparte y en general se publica, además una recomendación explícita, fue no enviar fotos ni videos sexuales o íntimos y no publicar nada que pueda ser manipulable. Sobre Controles y supervisión de los padres de familia sobre los menores de edad, en cuanto al uso 
de las redes sociales, un $18 \%$ de los encuestados, colocó a los padres de familia como responsables directos del control de las redes sociales de los menores de edad, mencionaron que debe existir un control directo y supervisión de los padres hacia los menores de edad, sobre el tiempo del uso de las redes y los aparatos electrónicos, así como una revisión sistemática de los contenidos y los historiales de búsqueda, por último, hacen referencia al hecho de que se debe evitar que los niños tengan acceso a aparatos electrónicos que los acerquen a las redes sociales. Con respecto al punto cuatro, los estudiantes manifiestan la necesidad de formación, con charlas y talleres en sus colegios, donde les ayuden a identificar y contrarrestar los peligros de las redes sociales, también donde se enseñe el uso adecuado del internet, sus políticas de seguridad y aplicaciones que tengan uso didáctico, de esta forma, además de ser un medio de distracción, se convierta en una herramienta de aprendizaje.

\section{Conclusiones}

El estudiantado de secundaria hace uso de dispositivos electrónicos para comunicarse por internet, principalmente el teléfono celular, seguido por la computadora, las redes sociales que más utilizan en orden de importancia son WhatsApp, Facebook, Instagram y Snapchat, asimismo, se determinan diferencias en relación con conocer y aplicar políticas de seguridad y privacidad en el uso de redes sociales, ya que los encuestados indican que si poseen conocimiento, no obstante; eso no es suficiente ya que expresan no aplicarlas, situación que causa gran preocupación al no dimensionar los peligros y riesgos a los cuáles están expuestos.

Un aspecto relevante es que prácticamente la totalidad de población encuestada no asocia a las redes sociales con algún peligro y con la importancia de establecer medidas de protección, sino que lo ven como una forma de comunicarse, situación que causa mayor importancia al encontrar que más del $80 \%$ de los encuestados se encuentra solo cuando accede a redes sociales.

Los jóvenes a pesar de conocer los peligros del uso de las redes sociales sin medidas de Ciberseguridad e indicar tener conocimiento de cuáles son estas medidas, son confiados a la hora de no aplicarlas, exponiéndose a condiciones de vulnerabilidad en cuanto a la privacidad y seguridad de sus datos, o al tener prácticas riesgosas como la transmisión de imágenes y videos por las redes, así como contactar con desconocidos. 
No se encontraron otros estudios a nivel nacional para contrastar los rangos de personas que conocen en su círculo cercano y que sufren Ciberbulling al acceder a las redes sociales, sin embargo; al analizar y contrastar las respuestas sobre situaciones que son caracterizadas como acciones de este riesgo, se determina que han vivido acciones de esta índole, pero no perciben haberlo vivido. Ahora bien, cuando se les encuesta si conocen a un amigo o familiar que lo haya sufrido, este porcentaje si se compara con el de las situaciones que ellos han vivido.

En relación con los controles aplicados por los padres, demuestran la escasez de conocimiento en el tema de redes sociales y ciberseguridad, porque a pesar de que un alto porcentaje de los hogares ha tocado el tema de los peligros existentes en esta modalidad de comunicación, no aplica controles ni lineamientos sobre el tiempo, contenido y forma de uso; proceso fundamental en la formación en seguridad en la red de los jóvenes. Sí explican ciertos riesgos, los referentes al sentido común, por tanto, se sigue confirmando la necesidad de formación de los padres, pues se comprueba que las medidas contundentes no se aplican y que solo explicar, no da los mismos resultados que una informada aplicación de límites, así como un seguimiento continuo durante el tiempo que las manipulan, máxime cuando se consideran uno de los actores más importante en el proceso de formación de la juventud.

Asimismo, a pesar de que más de la mitad de los encuestados afirma recibir información en sus colegios sobre los peligros en el uso de redes sociales, se determina que, de las seis instituciones, solamente en dos, se comenta o instruye sobre el tema. Situación similar evidenciada con los padres de familia, lo cual demanda un mayor acompañamiento por los centros educativos en la educación integral del estudiantado.

Aunado a lo anterior, se determina que los jóvenes incursionan en el uso de las redes sociales a través de internet sin una orientación explícita para su uso, ya que aprendieron solos su manipulación, contexto que demanda acciones urgentes y sistemáticas. La formación en ciberseguridad enfocada en el uso correcto de redes sociales debe desarrollarse por todos los participantes en la acción didáctica, a saber: el docente, el estudiante y los padres de familia.

Los riesgos que presentan las redes sociales son muchos y están comprobados, el que solo una quinta parte de los jóvenes indique que sus padres si se les limitan el uso a las redes sociales, nos enfrenta a un problema de formación e información, que obliga, como ya se ha mencionado antes, a educar sistemáticamente a las nuevas generaciones, pero también, educar a los padres de familia, que desconocen quizá, el alcance, en términos negativos, que pueden tener las redes 
sociales hoy en día y por esa razón, además de no limitar las horas de sus hijos en las redes sociales, tampoco, consideren como necesario conocer la lista de los contactos y mucho menos, incluir filtros y asegurarse de que utilicen medidas de seguridad.

Hace falta un mayor compromiso y formación en temas de ciberseguridad tanto por el usuario, en este caso los y las adolescentes, así como por los padres de padres de familia e instituciones educativas.

\section{Referencias}

Arab, L. E. y Díaz, A. (2015). Impacto de las redes sociales e Internet en la adolescencia: Aspectos positivos y negativos. Revista Médica Clínica Las Condes, 26(1), 7-13. doi: https://doi.org/10.1016/j.rmclc.2014.12.001

Area, M. y Pessoa, T. (2012). De lo sólido a lo líquido, las nuevas alfabetizaciones ante los cambios culturales de la Web 2.0. Revista Comunicar, 38, 13-20. doi: 10.3916/C38-2012-02-01

Arias, F. (2006). Proyecto de Investigación: Introducción a la Metodología Científica. 6ta Edición. Editorial Episteme. Venezuela

Astorga, C. Schmidt, I. (2019). Peligros de las redes sociales: Cómo educar a nuestros hijos e hijas en ciberseguridad. Revista Electrónica Educare, 23(3), 1-24. doi: http://dx.doi.org/10.15359/ree.23-3.17

Barrantes, R. (2005). Investigación: Un camino al Conocimiento. San José: EUNED.

Dorantes Carrión, J. (2016). Redes sociales y el ciberbullying en la Universidad Veracruzana. Revista Ensayos Pedagógicos, 169-188. Recuperado a partir de https://www.revistas.una.ac.cr/index.php/ensayospedagogicos/article/view/9346

Hernández, R, Fernández, C. y Baptista, P. (2006). Metodología de la Investigación. Cuarta Edición. México: Mc Graw Hill.

López González, R., \& Alarcón Montiel, E. (2016). Jóvenes estudiantes de la Universidad Veracruzana interactuando en red: ¿Diferencias por género?. Revista Ensayos Pedagógicos, 75-91. Recuperado de https://www.revistas.una.ac.cr/index.php/ensayospedagogicos/article/view/9341

Ministerio de Planificación Nacional y Política Económica (MIDEPLAN). Índice de Desarrollo Social. Recuperado de https://www.mideplan.go.cr/indice-desarrollo-social 
Morales, T., Serrano C., Miranda D. A., y Santos, A. (2014). Ciberbullying, acoso cibernético y delitos invisibles. Experiencias psicopedagógicas. México: Universidad Autónoma del Estado de México. $\quad$ Recuperado de http://ri.uaemex.mx/bitstream/handle/20.500.11799/21576/L_515_0.pdf?sequence=4\&isAll owed=y

Municipalidad de Sarapiquí (2019). Datos Generales. Recuperado de https://sarapiqui.go.cr/nuestra-municipalidad/datos-generales/136-informacion-poblacional Programa Estado de la Nación. (2017). Sexto informe estado de la educación. San José, CR:. Disponible en https://www.estadonacion.or.cr/educacion2017/assets/parte-1-capitulo-4.pdf PROSIC. (2016). Capitulo2: Adolescencia, Socialización y Tic. Disponible en http://www.prosic.ucr.ac.cr/informe-2016

Ros Martín, M. (2009). Evolución de los servicios de redes sociales en Internet. Evolution of Social Network Services, 18(5), 552-557. doi:10.3145/epi.2009.sep.10 